\title{
Biosynthesis and Scavenging of Purines by Pathogenic Mycobacteria Including Mycobacterium leprae
}

\author{
By P. R. WHEELER \\ Department of Biochemistry, University of Hull, Hull HU6 $7 R X, U K$
}

(Received 21 April 1987)

\begin{abstract}
Purine biosynthesis de novo could not be detected in suspensions of Mycobacterium leprae isolated from armadillo tissue. In contrast, non-growing suspensions of other pathogenic mycobacteria, also isolated from infected host tissue did synthesize purines. Rates of synthesis, judged by incorporation of $\left[2-^{14} \mathrm{C}\right] \mathrm{glycine}$ or $\left[3-{ }^{14} \mathrm{C}\right]$ serine into nucleic acid purines were 600 times higher in $M$. microti and 110 times higher in $M$. avium - both isolated from infected mouse tissue - than the lowest possible rate detectable and therefore the highest possible rate in $M$. leprae. The rate of purine synthesis relative to purine scavenging (judged by comparing incorporation of $\left[3-{ }^{14} \mathrm{C}\right]$ serine and $\left[8^{-14} \mathrm{C}\right]$ hypoxanthine into nucleic acid purines in suspensions of mycobacteria) varied only slightly - 4-fold in $M$. microti and 6-fold in $M$. avium - whether organisms were harvested from media with or without purines, from media with a low nitrogen content but containing a purine, from mice or even with starved organisms. Thus, the failure of $M$. leprae to synthesize purines could not be explained as either a result of using non-growing mycobacteria in the incubations with ${ }^{14} \mathrm{C}$-labelled precursors or as repression or inhibition of synthesis de novo. It appears that $M$. leprae requires a supply of the purine ring from its environment. Nucleotides, which may be the major source of the purine ring in the intracellular environment, were not taken up directly by $M$. leprae but could be hydrolysed first to nucleosides and then taken up.
\end{abstract}

\section{INTRODUCTION}

The ability of bacteria to synthesize purines, or to acquire them from the environment is essential for growth, since purine nucleotides are essential in nucleic acid biosynthesis and energy metabolism.

Mycobacterium leprae can scavenge purines from the environment (Khanolkar \& Wheeler, 1983). Other pathogenic mycobacteria probably also scavenge purines (see Ramakrishnan et al., 1972) but in addition can synthesize purines de novo (i.e. from simple carbon and nitrogen sources), as shown by their ability to grow in culture media without added purines. However, preliminary studies have not resolved satisfactorily the question of whether purines can be synthesized de novo by $M$. leprae (Khanolkar \& Wheeler, 1983). M. leprae has not yet been cultured in the laboratory and it may need an external supply of some metabolic intermediates, possibly purines in order to grow. Since preformed purines would probably be available to mycobacteria growing in host tissue (Marz et al., 1979) the failure to detect their synthesis de novo in $M$. leprae might be a result of repression of synthesis (Nierlich \& Magasanik, 1971; Houlberg \& Jensen, 1983) - or inhibition of activity (Nierlich \& Magasanik, 1965; Turnbough \& Switzer, 1975) of the enzymes in the de novo synthetic pathway - by purines. Alternatively, $M$. leprae may be genuinely incapable of carrying out purine biosynthesis and thus be dependent on the host for a supply of preformed purines, as are, for example, Trichomonas vaginalis (Heyworth et al., 1982) and most malarial parasites (Sherman, 1979).

Abbreviation: ICTCA, ice-cold 5\%(w/v) trichloroacetic acid. 
In this study, the ability of $M$. leprae, $M$. avium and $M$. microti to scavenge purines from the environment, or to synthesize them de novo, has been investigated using organisms grown in experimental animals and, where possible, in cell-free culture media.

Since M. leprae is an intracellular parasite (Evans et al., 1973; Mor, 1983) and most molecules containing the purine ring are present inside cells as nucleotides (Hunting et al., 1981; Lesse et al., 1984), experiments were also devised to determine whether $M$. leprae takes up nucleotides directly. Normally, bulky charged molecules like nucleotides do not pass through biological membranes but some highly specialized parasites such as Rickettsia and Chlamydia species (see Moulder, 1985) are exceptional in that they have translocases which enable them to acquire ATP and possibly other nucleotides directly from their environment.

\section{METHODS}

Mycobacterial strains, growth and harvesting. $M$. leprae was grown in nine banded armadillos (Dasypus novemcinctus Linn.) while M. microti OV254 (from the National Institute for Medical Research, London, UK) and M. avium CR1/69 (from the AFRC Institute for Research in Animal Diseases, Compton, Berkshire, UK) were grown in CBA and C57 Black mice respectively. All animals were inoculated intravenously with suspensions of bacteria $\left(10^{8}\right)$ from infected animals, and bacteria were harvested by a method (World Health Organization, 1980) which yields highly purified suspensions and was used previously in metabolic studies (Wheeler, 1984; see Fig. 1 for outline of method). At the time of harvesting, armadillo liver or spleen contained $5 \times 10^{9}$ to $5 \times 10^{10} \mathrm{M}$. leprae organisms ( $\mathrm{g}$ wet wt) $)^{-1}$; mouse lungs contained $2 \times 10^{9}$ to $2 \times 10^{10} \mathrm{M}$. microti organisms ( $\mathrm{g}$ wet wt) ${ }^{-1}$; and mouse liver or spleen contained $10^{10}$ to $2 \times 10^{11} M$. avium organisms ( $\mathrm{g}$ wet wt) ${ }^{-1}$. Infection with $M$. avium CR1/69 was very similar in appearance to the systemic infection with $M$. lepraemurium. Other tissues, and the above tissues with lower counts of acid fast bacteria, were not used. Very approximately, $10^{10} \mathrm{M}$. leprae or M. microti or $2 \times 10^{10}$ M. avium weighed $1 \mathrm{mg}$ (dry wt).

Bacteria were harvested from infected tissue stored at $-70^{\circ} \mathrm{C}$ for up to 6 months. However, the values in Table 1 include some obtained using $M$. leprae from infected tissue which had been stored only for $24 \mathrm{~h}$ while the values in Table 2 include some obtained using $M$. microt $i$ isolated from lungs immediately after killing mice. No marked difference in ability to incorporate ${ }^{14} \mathrm{C}$-labelled substrates was observed between bacteria from tissues stored for different periods at $-70^{\circ} \mathrm{C}$ or between bacteria from stored and fresh tissue in the case of $\mathrm{M}$. microti.

M. avium and $M$. microti were also grown (Chadwick, 1982) in Modified Dubos Medium with or without added purines for 16 and $14 \mathrm{~d}$ respectively. Additionally, M. avium was grown in Youmans and Karlson medium for $18 \mathrm{~d}$. When the bacteria were to be used for experiments after growth (see Fig. 1), the flasks including growth medium were inoculated with a suspension of bacteria $(1 \mathrm{ml})$ grown in the same medium. All growth was at $37^{\circ} \mathrm{C}$ in $100 \mathrm{ml}$ medium in shaken ( 200 r.p.m.) $250 \mathrm{ml}$ flasks stoppered with polyurethane bungs. Suspensions were prepared for adding to incubation media (below) by washing aseptically the bacteria three times in buffered Tween $80(0.1 \%$, w/v, Tween 80 in 1.5 mM-MES, pH 7.0).

Radioisotopically labelled substrates. These were supplied at the following specific activities. Amino acids: [2$\left.{ }^{14} \mathrm{C}\right] \mathrm{glycine}\left(56 \mathrm{Ci} \mathrm{mol}^{-1}\right),\left[{ }^{-14} \mathrm{C}\right]$ serine $\left(53 \mathrm{Ci} \mathrm{mol}^{-1}\right)$. Purine bases: $\left[8{ }^{-14} \mathrm{C}\right]$ hypoxanthine $\left(52 \mathrm{Ci} \mathrm{mol}^{-1}\right),\left[\mathrm{G}-{ }^{3} \mathrm{H}\right]-$ hypoxanthine $\left(2.8 \mathrm{Ci} \mathrm{mmol}^{-1}\right),\left[8^{-14} \mathrm{C}\right]$ adenine $\left(54 \mathrm{Ci} \mathrm{mol}{ }^{-1}\right)$ and $\left[8^{-14} \mathrm{C}\right]$ guanine $\left(51 \mathrm{Ci} \mathrm{mol}^{-1}\right)$. Purine nucleosides: $\left[8{ }^{-14} \mathrm{C}\right]$ adenosine $\left(56 \mathrm{Ci} \mathrm{mol}^{-1}\right)$ and $\left[8{ }^{-3} \mathrm{H}\right]$ guanosine $\left(5 \mathrm{Ci} \mathrm{mmol}^{-1}\right)$. Purine nucleotides: [U$\left.{ }^{14} \mathrm{C}\right] \mathrm{GMP}\left(526 \mathrm{Ci} \mathrm{mol}^{-1}\right)$ and $\left[2-{ }^{-3} \mathrm{H}\right] \mathrm{AMP}\left(19 \cdot 3 \mathrm{Ci} \mathrm{mmol}^{-1}\right) .(1 \mathrm{Ci}=37 \mathrm{GBq}$.) All were supplied by Amersham except guanine which was supplied by New England Nuclear.

Incubations with radioisotopically labelled substrates. Intact mycobacteria $\left(4 \times 10^{9}\right.$ to $\left.7 \times 10^{10}\right)$ were incubated at $34^{\circ} \mathrm{C}$ for $24 \mathrm{~h}$ (occasionally, $144 \mathrm{~h}$ ) in the following filter sterilized incubation medium, which did not support growth of the mycobacteria used in this study: $50 \mathrm{~mm}$-HEPES, $5 \mathrm{~mm}-\mathrm{NaCl}, 1 \mathrm{~mm}-\mathrm{MgSO}_{4}, 0.2 \mathrm{~mm}-\mathrm{NaH}_{2} \mathrm{PO}_{4}$, $17 \mathrm{mM}$-L-asparagine, $55 \mathrm{mM}$-glucose, $10 \mu \mathrm{M}$-uracil, $10 \mu \mathrm{M}$-thymidine and $10 \mu \mathrm{M}$-cytosine, adjusted to $\mathrm{pH} 7$ with $6 \mathrm{M}-\mathrm{KOH}$. For most of the incubations (represented in Tables 1 to 5 ), ${ }^{14} \mathrm{C}$-labelled amino acids were added at $100 \mu \mathrm{M}$, and ${ }^{14} \mathrm{C}$-labelled purines and purine nucleosides at $80 \mu \mathrm{M}$. The incubation volume was always $300 \mu \mathrm{l}$ and the following amounts of radiolabelled amino acids or purines were included : glycine, $1.68 \mu \mathrm{Ci}$; serine, $1.59 \mu \mathrm{Ci}$; hypoxanthine, $1.25 \mu \mathrm{Ci}$; adenine, $1.30 \mu \mathrm{Ci}$; guanine, $1.22 \mu \mathrm{Ci}$; adenosine, $1.34 \mu \mathrm{Ci}$. $(1 \mu \mathrm{Ci}=37 \mathrm{kBq}$. $)$ These amounts represent labelled substrates (listed above) added to incubation mixtures without dilution with unlabelled substrates. In experiments designed to investigate uptake of purine nucleotides (see Table 6), either ${ }^{3} \mathrm{H}$ - or ${ }^{14} \mathrm{C}$ labelled nucleotides or purine nucleosides were added at $17 \mu \mathrm{M}$ and $1 \mu \mathrm{Ci}$, unlabelled substrates being added where necessary. Controls contained heat killed $\left(100^{\circ} \mathrm{C}, 15 \mathrm{~min}\right)$ bacteria. In the results, d.p.m. in controls are always subtracted.

Experiments with mycobacteria grown in the presence of radiolabelled purines. Mycobacteria were grown at $37^{\circ} \mathrm{C}$ in Modified Dubos Medium $(100 \mathrm{ml})$ as described above with either $80 \mu \mathrm{M}$-adenine including $2 \mu \mathrm{Ci}\left[8^{-14} \mathrm{C}\right]$ adenine 
In vitro

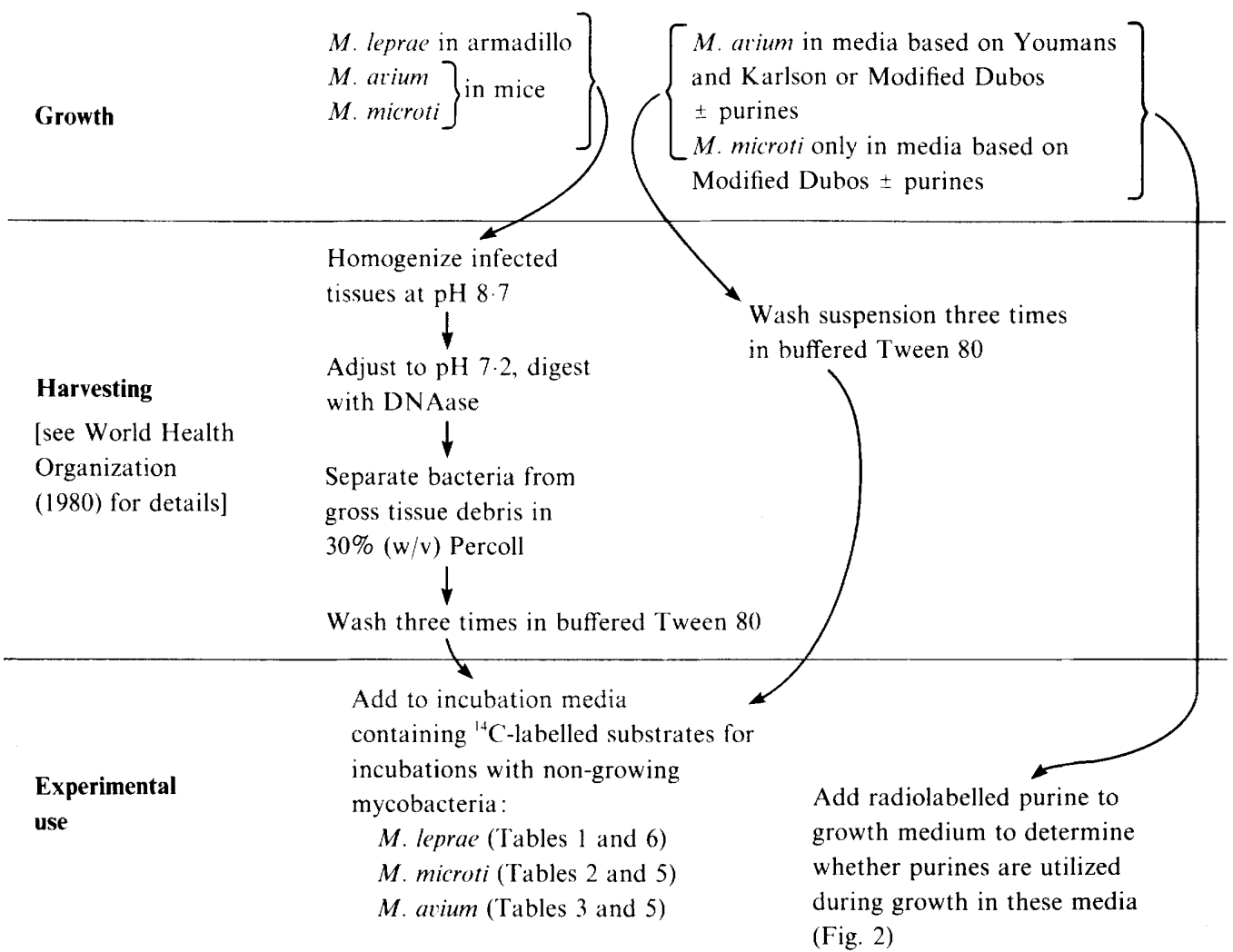

Fig. 1. Growth and use of mycobacteria for experimental work on purine metabolism.

or $80 \mu \mathrm{M}$-hypoxanthine including $5 \mu \mathrm{Ci}\left[\mathrm{G}^{-3} \mathrm{H}\right]$ hypoxanthine. Samples $(2 \mathrm{ml})$ were taken at intervals (up to six) during growth so that at the end of the experiment, there was still at least $88 \mathrm{ml}$ culture medium in each flask. The final sample was $40 \mathrm{ml}$. For each sample, $\mathrm{OD}_{550}$ was measured to determine cell density, and then the bacteria and culture medium were separated by centrifugation. Purines in the nucleic acids of the bacteria were obtained as described below. Purines in the culture medium were extracted once into an equal volume of butan-1-ol so that they could be separated cleanly by TLC. The yield of each purine extracted into butan-1-ol was determined ( 40 to $50 \%$ depending on the purine) using known amounts of radiolabelled purine so results in these experiments were calculated taking the yield into account. Butan-1-ol extracts were dried in a stream of nitrogen, redissolved in $10 \mu l$ $0 \cdot 1 \mathrm{M}-\mathrm{HCl}$, applied to Chromogram cellulose TLC plates (Kodak-Eastman) as $1 \mathrm{~cm}$ streaks and separated by development with propan-2-ol/5 $\mathrm{M}-\mathrm{HCl}(10: 7, \mathrm{v} / \mathrm{v})$ only. Areas of the TLC plate including purines were identified under UV light $(254 \mathrm{~nm})$, cut out, and their radioactivity was determined. Plots of $\mathrm{OD}_{550}$ of suspensions of mycobacteria against dry weight of organisms were indistinguishable after either 7 or $16 \mathrm{~d}$ growth so $\mathrm{OD}_{550}$ determinations were used routinely to determine growth, and were only confirmed by weighing at the end of each growth experiment.

Analysis of incubation products. At the end of incubation periods, or when harvesting bacteria grown in flasks, samples were taken to check for any contamination by fast growing bacteria by spreading $10 \mu 1$ on to nutrient agar plates. Results obtained from contaminated incubations or flasks were discarded. Further samples were taken to measure $(a)$ uptake, $(b)$ incorporation into acid insoluble material, $(c)$ incorporation into the purines of nucleic acids, and $(d)$ assimilation of radiolabel into nucleotides, as required.

(a) Uptake of radiolabelled substrates. Uptake was determined by collecting incubation mixtures on Whatman GFC filters and washing four times with $15 \mathrm{ml}$ cold, buffered Tween 80 . Filters were dried and radioactivity was determined. 
(b) Incorporation of radioactivity into acid insoluble material. Incubation mixtures were collected and washed as for uptake determinations, then washed three times in ice-cold $5 \%(w / v)$ trichloroacetic acid (ICTCA) and once in methanol. Filters were dried and radioactivity was determined.

(c) Incorporation of radioactivity into the purines of nucleic acids. Incubation mixtures were collected and washed as for uptake determinations then $100 \mu \mathrm{g}$ yeast RNA (from Torula: Sigma) precipitated with ICTCA was collected on each filter as a carrier since little nucleic acid would be obtained from the mycobacteria (about $1 \mathrm{mg} \mathrm{dry} \mathrm{wt)}$ applied. Each filter was washed three times with $15 \mathrm{ml}$ ICTCA then once with methanol. The filters were macerated in $1 \mathrm{ml} \mathrm{ICTCA}$, heated at $90{ }^{\circ} \mathrm{C}$ for $15 \mathrm{~min}$, and the eluates collected by filtration through pre-wetted Millex GS (Millipore) filters. Eluates were heated at $100^{\circ} \mathrm{C}$ for $2 \mathrm{~h}$ to destroy the trichloracetic acid, dried, and then the nucleic acids isolated were hydrolysed with $1 \mathrm{M}-\mathrm{HCl}$ for $1 \mathrm{~h}$ at $100^{\circ} \mathrm{C}$. Hydrolysates were dried, reconstituted in $20 \mu \mathrm{l} 0 \cdot 1 \mathrm{M}-\mathrm{HCl}$ and then each was applied as a spot on to a Chromogram cellulose TLC plate with fluorescent indicator. The plates were developed in butan-1-ol/ $\mathrm{NH}_{4} \mathrm{OH}$ (sp. gr. 0.880)/distilled $\mathrm{H}_{2} \mathrm{O}(86: 5: 14$, by vol.; top layer used), dried thoroughly, and then developed perpendicular to the first development in propan-2-ol/ $5 \mathrm{M}-\mathrm{HCl}(10: 7, \mathrm{v} / \mathrm{v})$ in the second dimension. This successfully separated purines from each other and from amino acids except that there was some risk of contamination of guanine with cysteine. Therefore, guanine and cysteine were resolved by cutting out the appropriate part of the TLC plate and developing in distilled water, in the first direction. Areas of the TLC plate with purines were identified under UV light at $254 \mathrm{~nm}$, cut out, and radioactivity was determined in the pieces of TLC plate.

The above methods, essentially an adaptation for use with small samples and very little radioactivity, of methods used with $M$. tuberculosis (Malathi \& Ramakrishnan, 1966) gave yields of 55 to $85 \%$ as judged by determining radioactivity in guanine and adenine separated by TLC and dividing by the radioactivity in the total nucleic acid material (eluate from Millex GS filter) with $M$. avium and $M$. microti but only about 20 to $30 \%$ with $M$. leprae (using $\left[8^{-14} \mathrm{C}\right]$ hypoxanthine as the source of label). Usually, very little or no radioactivity was detected in spots on the TLC plate corresponding to glycine, serine or hypoxanthine, showing that the total nucleic acid material was not contaminated with substantial protein or the radioisotopically labelled substrate used in incubations. Thus, the methods were suitable for their intended purpose.

(d) Assimilation of radioactivity into nucleotides. Essentially, the same procedure as $(c)$ was used and when ICTCA was applied and used to wash the filters, the filtrate was collected. However, instead of washing with $3 \times$ $15 \mathrm{ml}$ ICTCA filters were washed first with $2 \times 5 \mathrm{ml} \mathrm{ICTCA}$, then $2 \times 15 \mathrm{ml}$ ICTCA. Only the filtrate from the first $2 \times 5 \mathrm{ml}$ was collected, heated at $100^{\circ} \mathrm{C}$ for $2 \mathrm{~h}$, and then dried. Each dried filtrate was dissolved in $50 \mu \mathrm{l}$ $1 \mathrm{~mm}$-ammonium formate and spotted on to a Whatman DE-81 filter wetted with distilled water. Each DE-81 filter was washed twice with distilled water, three times with $1 \mathrm{~mm}$-ammonium formate, and then radioactivity on the filter was determined. This procedure gave a high, consistent yield of nucleotides retained on the filter (about $70 \%)$ with very little retention of amino acids $(<0.2 \%)$ or hypoxanthine $(<0.5 \%)$.

Determination of radioactivity. $\mathrm{HCl}(150 \mu \mathrm{l}$ at $0 \cdot 1 \mathrm{M})$ was added to filters or pieces of TLC plate; $10 \mathrm{~min}$ later $10 \mathrm{ml}$ Bray's scintillation fluid was added and radioactivity was determined in a liquid-scintillation counter.

\section{RESULTS AND DISCUSSION}

\section{Synthesis and scavenging of purines by intact $M$. leprae}

No radioactivity from either $\left[{ }^{14} \mathrm{C}\right]$ glycine or $\left[{ }^{14} \mathrm{C}\right]$ serine supplied in the incubation medium was incorporated into purines in nucleic acids or into purine nucleotides in $M$. leprae (Table 1 ). However, glycine and serine were both taken up by $M$. leprae (Table 1) so the failure of the bacteria to use them in purine synthesis could not be explained as a failure to take up the two precursors of purine synthesis. Preincubating M. leprae organisms in buffered Tween 80 is known to enhance incorporation of hypoxanthine into nucleic acids (Wheeler, 1988) probably as a result of depleting at least some intracellular nucleotides (Lee \& Colston, 1985). However, when $M$. leprae organisms were incubated in buffered Tween 80 at $34{ }^{\circ} \mathrm{C}$ for $24 \mathrm{~h}$ or $72 \mathrm{~h}$ before adding to incubation medium with $\left[{ }^{14} \mathrm{C}\right]$ glycine or $\left[{ }^{14} \mathrm{C}\right]$ serine no incorporation of radioactivity into purine occurred. Futhermore, no purine synthesis occurred even if $M$. leprae organisms were incubated for $144 \mathrm{~h}$ with or without preincubating in buffered Tween 80 .

Incorporation of purines from the incubation medium into nucleic acids was shown in incubations with $\left[{ }^{14} \mathrm{C}\right]$ hypoxanthine and $\left[{ }^{14} \mathrm{C}\right]$ adenosine (Table 1), confirming (while using a more rigorous method for separating purines) the previous observations of purine scavenging by $M$. leprae (Khanolkar \& Wheeler, 1983). Nucleotides were collected in a further attempt to detect purine synthesis de novo but no radioactivity was incorporated into nucleotides from either $\left[{ }^{14} \mathrm{C}\right]$ serine or $\left[{ }^{14} \mathrm{C}\right]$ glycine while little was incorporated even from ${ }^{14} \mathrm{C}$-labelled purines in the medium (Table 1). 
Table 1. Purine synthesis and scavenging by M. leprae

Incubations were at $34^{\circ} \mathrm{C}$. Three to seven incubations were done for each result (the actual number is shown for negative results) using $M$. leprae organisms isolated from two to five armadillos. All values are d.p.m. incorporated/taken up in $24 \mathrm{~h}$ by $10^{10}$ organisms, $\pm \mathrm{SEM}$.

${ }^{1+} \mathrm{C}$-Labelled substrate

$\left[3^{-14} \mathrm{C}\right]$ Serine

$\left[2-{ }^{14} \mathrm{C}\right]$ Glycine

$\left[8^{-14} \mathrm{C}\right]$ Hypoxanthine

$\left[8^{-14} \mathrm{C}\right]$ Adenosine

ND, Not done.

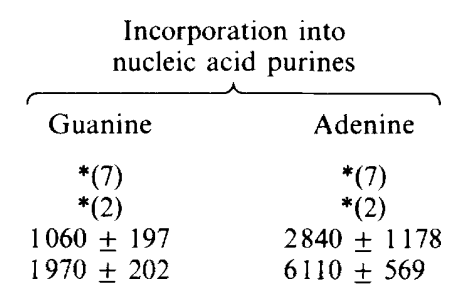

Incorporation into nucleotides $5740 \pm 814$ $8010 \pm 400$ $28800 \pm 5640$ $47800 \pm 6012$

$$
\begin{gathered}
*(4) \\
*(2) \\
1240 \pm 111 \\
\text { ND }
\end{gathered}
$$

${ }^{*}$ Not detectable; as little as 4 d.p.m. $(\mathrm{mg} \text { protein })^{-1}$ could be detected since up to $7 \times 10^{10} \mathrm{M}$. leprae organisms were used.

\title{
Table 2. Purine synthesis and scavenging by $M$. microti
}

\begin{abstract}
Incubations were at $34^{\circ} \mathrm{C}$ and included $4 \times 10^{9}$ to $1 \cdot 2 \times 10^{10}$ organisms. Two to six incubations were

\begin{tabular}{|c|c|c|c|c|c|}
\hline \multirow{3}{*}{$\begin{array}{c}{ }^{14} \mathrm{C} \text {-Labelled } \\
\text { substrate in } \\
\text { incubation medium }\end{array}$} & \multirow[b]{3}{*}{ Purine } & \multicolumn{4}{|c|}{ Incorporation into nucleic acid purines } \\
\hline & & \multicolumn{4}{|c|}{ Growth medium: } \\
\hline & & Dubos & $\begin{array}{c}\text { Dubos }+ \\
80 \mu \mathrm{M} \text {-adenine }\end{array}$ & $\begin{array}{c}\text { Dubos }+ \\
80 \mu \mathrm{M} \text {-hypoxanthine }\end{array}$ & $\begin{array}{l}\text { Mice* } \\
\text { (CBA) }\end{array}$ \\
\hline$\left[3^{-1+C} \mathrm{C}\right]$ Serine & G & $1010 \pm 237$ & $698 \pm 132$ & $323 \pm 1$ & $1580 \pm 369$ \\
\hline & A & $1580 \pm 350$ & $1290 \pm 198$ & $450 \pm 96$ & $2410 \pm 807$ \\
\hline$[2-1+C]$ Glycine & G & $346 \pm 15$ & $140 \pm 15$ & ND & $724 \pm 110$ \\
\hline & A & $389 \pm 27$ & $208 \pm 1$ & ND & $1120 \pm 245$ \\
\hline$\left[8-^{1+} \mathrm{C}\right]$ Hypoxanthine & G & $9730 \pm 2055$ & $10400 \pm 2636$ & $9400 \pm 3149$ & $10700 \pm 1327$ \\
\hline & A & $11600 \pm 2625$ & $10400 \pm 2706$ & $10000 \pm 2373$ & $16000 \pm 1819$ \\
\hline$\left[8-^{14} \mathrm{C}\right]$ Adenine & G & $2200 \pm 397$ & $2490 \pm 741$ & $2590 \pm 1030$ & $1730 \pm 327$ \\
\hline & A & $15100 \pm 1204$ & $12100 \pm 2329$ & $10700 \pm 3449$ & $20100 \pm 3318$ \\
\hline
\end{tabular}
done for each result. Usually, each of these incubations was from a separate isolate or culture of $M$. microti OV254. All values are d.p.m. incorporated in $24 \mathrm{~h}$ per $10^{10}$ organisms, \pm SEM. Abbreviations: $\mathrm{G}$, guanine, $\mathrm{A}$, adenine.
\end{abstract}

ND, Not done.

* When $M$. microti organisms harvested from mice were treated with $0.5 \mathrm{M}-\mathrm{NaOH}$ at $25^{\circ} \mathrm{C}$ for 30 mins to abolish any possible contamination from host-derived activities, incorporation of radioactivity into nucleic purines was still observed, at the following rates relative to those reported above: in incubations with serine, $46 \%$; with glycine, $61 \%$; with hypoxanthine, $68 \%$.

\section{Comparison of purine synthesis and scavenging by intact $M$. microti and $M$. avium}

The lack of purine biosynthesis in suspensions of $M$. leprae may reflect an inability of the bacteria to synthesize the purine ring themselves. However, it may be that $(a)$ it is not possible to demonstrate purine synthesis in non-dividing mycobacteria or $(b)$ purine biosynthesis is repressed in mycobacteria grown in vivo and therefore would not be detected in $M$. leprae isolated from armadillo tissues. To determine whether $(a)$ or $(b)$ above could explain the lack of purine synthesis in M. leprae, two cultivabie pathogenic mycobacteria (M. microti and M. avium) were grown in experimental animals or culture media, harvested, and suspensions were prepared (Fig. 1). The suspensions were then incubated for $24 \mathrm{~h}$ without growth in 'incubation medium' containing ${ }^{1+} \mathrm{C}$-labelled substrates (Fig. 1). Incorporation of $\left[{ }^{14} \mathrm{C}\right]$ glycine or $\left[{ }^{14} \mathrm{C}\right]$ serine from the incubation medium into nucleic acid purines is referred to as 'purine synthesis' while incorporation of ${ }^{1+} \mathrm{C}$-labelled purines from incubation medium into nucleic acids is referred to as 'purine scavenging'. Clearly, purine synthesis occurred in suspensions of both non-growing M. microti (Table 2) and M. avium (Table 3). 


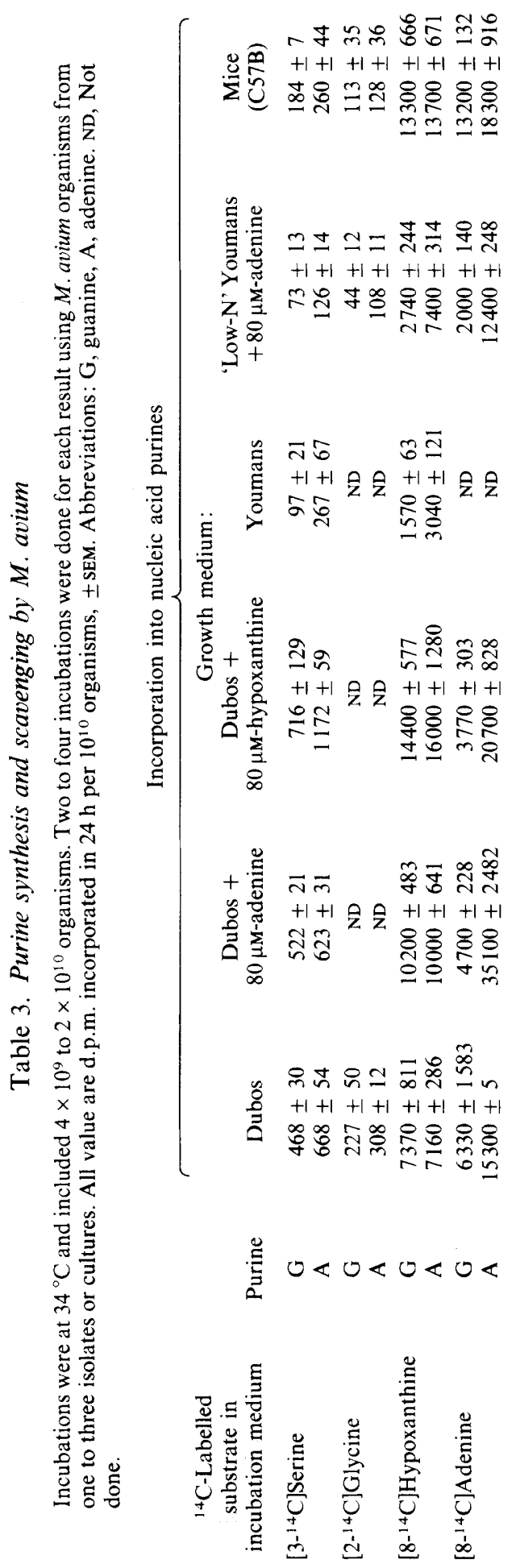


Purine synthesis was readily detected in both $M$. microti (Table 2) and $M$. avium (Table 3) grown in mice, or in liquid media to which purines had been added. If rates of purine synthesis are considered in isolation, the results obtained with $M$. microti and $M$. avium appear somewhat paradoxical. In $M$. avium, the rate of purine synthesis was 2 to 3 times lower in the bacteria isolated from mouse tissue than in bacteria from Dubos medium (Table 3). Conversely, the rate of purine synthesis was slightly higher in $M$. microti organisms obtained from mice, even though purines might be available in host tissue. However, the rate of purine scavenging activity was also higher in $M$. microti grown in vivo (Table 2). Such variation in metabolic activities may reflect differences in growth rate, the metabolic state of organisms or the proportion of bacteria in a suspension that are viable. Indeed, both the activities of purine synthesis and scavenging reported here for $M$. avium grown in media based on Youmans and Karlson medium are relatively low (Table 3 ).

Thus it became clear that to assess the contribution of purine biosynthesis to metabolism in mycobacteria grown in different conditions it would be necessary to compare rates of purine synthesis and purine scavenging in the same suspensions of mycobacteria. In order to make comparisons easily, the relative rates of synthesis and scavenging are expressed as a 'purine biosynthetic index' (Table 4), the value of which is higher when organisms are tending to synthesize rather than scavenge purines.

The value of the purine biosynthetic index was highest in $M$. microti grown in Dubos medium and only slightly lower in $M$. microti grown in mice or in Dubos medium including adenine (Table 4). However, when $M$. microti was grown in Dubos medium plus $80 \mu \mathrm{M}$-hypoxanthine, the purine biosynthetic index was three to four times lower than when it was grown in Dubos medium alone (Table 4). For $M$. avium, inclusion of purines in Dubos medium had little effect on the purine biosynthetic index in the bacteria. However, it was possible to grow $M$. avium (but not $M$. microti which even in optimal media grows only poorly) in media based on Youmans and Karlson medium but with only $20 \%$ of the original nitrogen content (referred to as 'Low-N' Youmans in Tables 3 to 5) plus a purine at $80 \mu \mathrm{M}$ : when the purine added was adenine (Table 3), the purine biosynthetic index in $M$. avium organisms was four times lower than in $M$. avium grown in Youmans and Karlson medium alone (Table 4). Even so, the purine biosynthetic index in $M$. avium grown in vitro was never lower than the index in $M$. avium grown in mice.

\section{Is repression or inhibition of purine synthesis relieved during $24 \mathrm{~h}$ incubations?}

The effects described above on purine biosynthesis in either $M$. microti or $M$. avium are small compared with other bacteria (see Introduction for references). Therefore, further experiments were designed to test $(a)$ the possibility that during the $24 \mathrm{~h}$ incubation with ${ }^{14} \mathrm{C}$ precursor, any inhibition of purine synthesis that occurred during growth might be relieved, and $(b)$ whether purines were being utilized by $M$. microti and $M$. avium in the growth conditions being used. In the latter case repression or inhibition of purine synthesis might not occur at all if purines were not being utilized.

To test whether inhibition of purine biosynthesis is relieved, unlabelled purines were added at the concentration at which they were supplied during growth to incubation mixtures containing ${ }^{14} \mathrm{C}$-labelled purine precursors (Table 5). Only the addition of adenine to incubations of $M$. microti which had been grown in Dubos medium containing adenine resulted in any marked inhibition of purine synthesis (Table 5). Addition of hypoxanthine to incubations resulted in slight (no more than 52\%) inhibition of purine biosynthesis in most incubations but apparent stimulation of purine biosynthesis in two incubation mixtures (Table 5).

Since addition of purines to incubation medium does not consistently result in strong inhibition of purine synthesis (i.e. a putative low activity of purine synthesis is not restored) it appears that inhibition or repression of purine biosynthesis is not being relieved during the $24 \mathrm{~h}$ incubations (shown in Tables 2 and 3) without purines present at $80 \mu \mathrm{M}$.

\section{Utilization of purines by $M$. microti and $M$. avium}

Purines, when supplied in the growth medium, were clearly used by both $M$. microti and $M$. avium. In experiments where labelled purines were included in the growth medium they were 


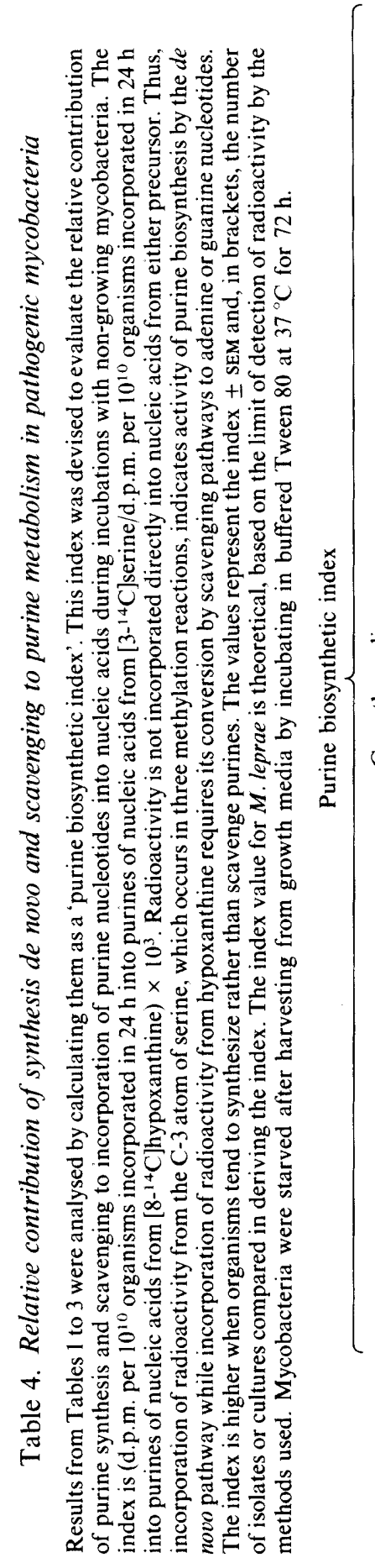

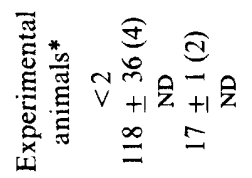$$
\text { 统 }
$$$$
\text { 客 }
$$$$
+\infty
$$

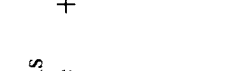$$
\text { 离. }
$$ 
Table 5. Effect of adding unlabelled purines to incubations containing ${ }^{14} \mathrm{C}$-labelled amino acids

Incubations were at $34^{\circ} \mathrm{C}$ and included $4 \times 10^{9}$ to $2 \times 10^{10}$ organisms. Two to four incubations were done for each result using organisms from one to three isolates. Results are expressed as percentages of radioactivity incorporated in similar incubations but without unlabelled purines. They were calculated as follows: (d.p.m. per $10^{10}$ organisms incorporated in $24 \mathrm{~h}$ when unlabelled purines, at $80 \mu \mathrm{M}$, were included in incubations)/(d.p.m. per $10^{10}$ organisms incorporated in $24 \mathrm{~h}$ in incubations without unlabelled purines). The mean of the percentage values obtained from each isolate or culture \pm SEM is given below. Note that actual values of radioactivity incorporated (d.p.m. per $10^{10}$ organisms in $24 \mathrm{~h}$ ) in incubations without unlabelled purines are given in Tables 2 and 3.

\begin{tabular}{|c|c|c|c|c|}
\hline \multirow[b]{2}{*}{ Organism } & \multirow[b]{2}{*}{ Growth medium } & \multicolumn{3}{|c|}{$\begin{array}{l}\text { Radioactivity incorporated into nucleic acid purines } \\
\text { from incubation medium containing: }\end{array}$} \\
\hline & & $\begin{array}{l}{[3-1+\text { C }] \text { Serine }} \\
+ \text { adenine }\end{array}$ & $\begin{aligned} & {\left[3-{ }^{1+} \mathrm{C}\right] \text { Serine } } \\
+ & \text { hypoxanthine }\end{aligned}$ & $\begin{array}{l}{\left[2-1^{14} \text { C }\right] \text { Glycine }} \\
+ \text { adenine }\end{array}$ \\
\hline M. microti & $\begin{array}{l}\text { Dubos } \\
\text { Dubos }+80 \mu \mathrm{M} \text {-adenine } \\
\text { Dubos }+80 \mu \mathrm{M} \text {-hypoxanthine } \\
\text { Mice }(\mathrm{CBA})\end{array}$ & $\begin{array}{l}74 \pm 16 \\
29 \pm 6 \\
89 \pm 41 \\
72 \pm 19\end{array}$ & $\begin{array}{c}93 \pm 34 \\
48^{*} \\
135^{*} \\
66^{*}\end{array}$ & $\begin{array}{l}\text { ND } \\
\text { ND } \\
\text { ND } \\
\text { ND }\end{array}$ \\
\hline M. avium & $\begin{array}{l}\text { Dubos }+80 \mu \mathrm{M} \text {-adenine } \\
\text { 'Low-N' Youmans }+80 \mu \mathrm{M} \text {-adenine } \\
\text { Mice (C57 Black) }\end{array}$ & $\begin{aligned} 83 & \pm 8 \\
112 & \pm 16 \\
78 & \pm 17\end{aligned}$ & $\begin{array}{l}\text { ND } \\
88 \pm 20 \\
\text { ND }\end{array}$ & $59 \stackrel{\text { ND }}{76^{*}}$ \\
\hline
\end{tabular}

shown to be incorporated into nucleic acid of the growing organisms, and to be metabolized to other purines (Fig. 2).

Scavenging only of hypoxanthine and adenine is shown in Tables 2 and 3. However (in similar incubations, but with other ${ }^{14} \mathrm{C}$-labelled purines), adenosine was scavenged by both $M$. microti and $M$. avium at about $70 \%$ of the rate of adenine scavenging, and scavenging of guanine, at about $50 \%$ of the rate of adenine scavenging, was shown in $M$. microti. Details of the rates of scavenging of adenosine and guanine are not shown, but the rates relative to scavenging of adenine were similar for mycobacteria grown in Dubos medium or in mice. Thus $M$. microti and $M$. avium, like $M$. leprae (Table 1 ; see also Khanolkar \& Wheeler, 1983) are able to scavenge a wide range of purines, convert them to other purines, and incorporate them into nucleic acids. However, their 'order of preference' for purines is different from that of $M$. leprae.

\section{M. leprae fails to synthesize purines}

In a final attempt to obtain $M$. microti or $M$. avium organisms synthesizing purines at a very low rate, organisms were starved by incubating them in buffered Tween 80 at $37^{\circ} \mathrm{C}$ for $24 \mathrm{~h}$ (results not shown) or $72 \mathrm{~h}$. When bacteria starved for $72 \mathrm{~h}$ were added to incubation mixtures including either $\left[{ }^{14} \mathrm{C}\right] \mathrm{glycine}$ or $\left[{ }^{14} \mathrm{C}\right]$ serine as purine precursor, purine synthesis occurred at only about $30 \%$ of the rate of purine synthesis in freshly harvested bacteria. However, rates of incorporation of hypoxanthine or adenine were also lower in starved mycobacteria. Detailed results are not presented here, but values of the purine biosynthetic index in bacteria starved for $72 \mathrm{~h}$ are shown in Table 4 . Compared with freshly harvested bacteria, the value of the purine biosynthetic index decreased only about twofold in starved $M$. microti, while in $M$. avium the value of the index increased in $M$. avium from Dubos medium containing adenine.

Thus, only very weak repression or inhibition of purine synthesis could be demonstrated in either $M$. microti and $M$. avium regardless of how they were grown. In contrast, purine synthesis could not be shown in $M$. leprae.

Uptake over $24 \mathrm{~h}$ of the precursors of purine biosynthesis $\left[{ }^{14} \mathrm{C}\right]$ glycine and $\left[{ }^{1+} \mathrm{C}\right]$ serine by $M$. microti and $M$. avium (whether grown in Dubos medium, Dubos medium plus a purine, or mice; results not shown in detail) was 1.5 to 4.5 times higher than by $M$. leprae (Table 1) but greater numbers of $M$. leprae organisms were used in incubations to compensate for this. Taking into account numbers of bacteria used and the sensitivity of methods, the purine biosynthetic index 

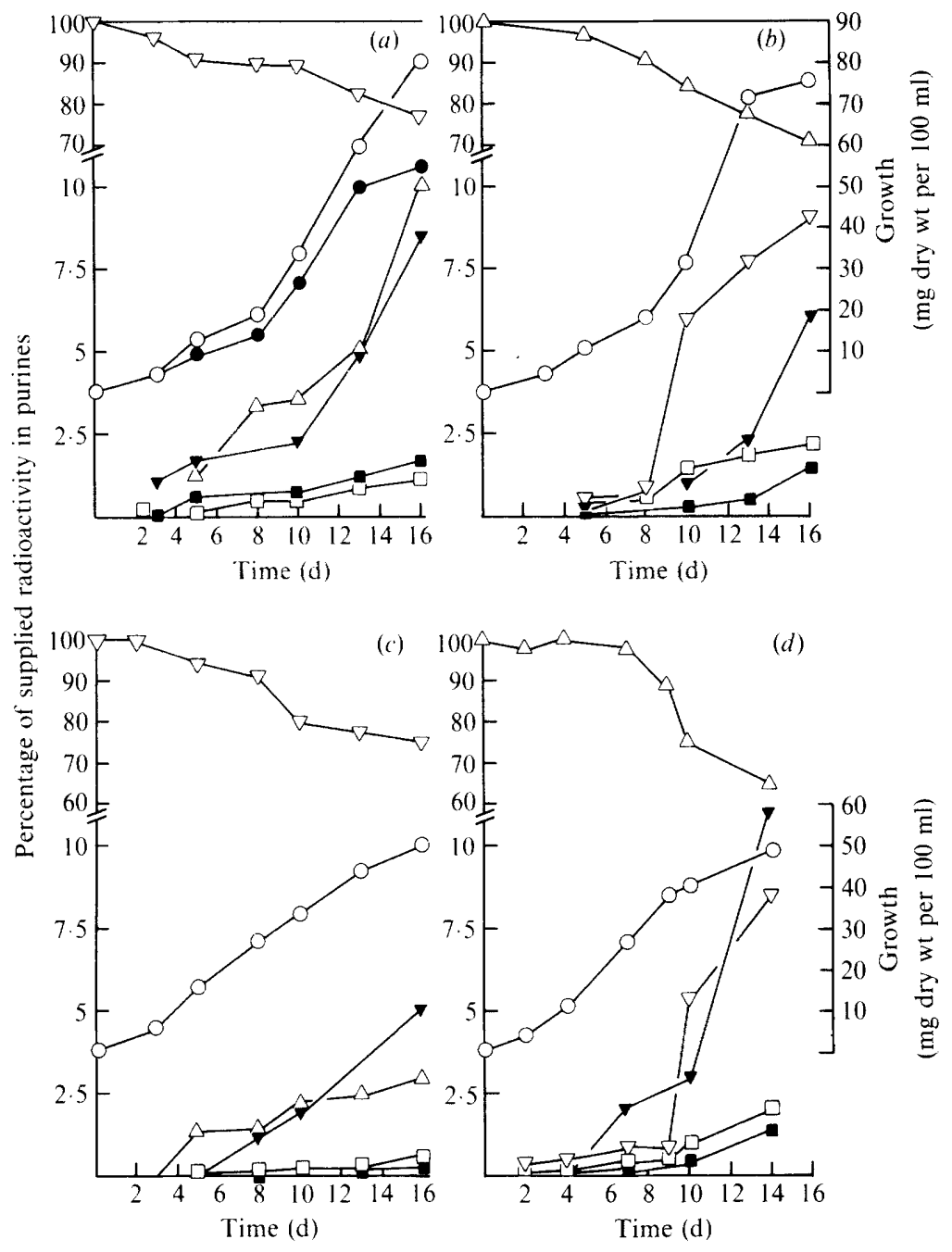

Fig. 2. Growth of mycobacteria and their utilization of purines in growth media. $(a, b) M$. avium $\mathrm{CR} 1 / 69 ;(c, d) \mathrm{M}$. microti OV254. $(a, c)$ Dubos medium $+80 \mu \mathrm{M}$-adenine, including $2 \mu \mathrm{Ci}\left[8^{-14} \mathrm{C}\right]-$ adenine; $(b, d)$ Dubos medium $+80 \mu \mathrm{M}$-hypoxanthine, including $5 \mu \mathrm{Ci}\left[\mathrm{G}-{ }^{3} \mathrm{H}\right]$ hypoxanthine. Purines in the culture medium are represented by open symbols, purines recovered from nucleic acids of the bacteria with filled symbols: $\square$, $\square$, guanine; $\triangle$, hypoxanthine; $\nabla, \nabla$, adenine. $\bigcirc$, Growth; additionally, growth of $M$. avium in the absence of purines is represented in $(a)$ by the symbol Growth of $M$. microti was not enhanced by purines. Results from representative experiments are shown. Two separate experiments were done, except in the case of the growth curve for $M$. microti where three experiments were done. Variation was as follows: for percentage of supplied radioactivity in purines, $\pm 3 \%$ of the values shown; for growth, $\pm 20 \%$ of the values shown. In the absence of bacteria the distribution of radioactivity in purines in the culture medium was the same after $16 \mathrm{~d}$ at $37^{\circ} \mathrm{C}$ as in flasks immediately after radioactive purines were added.

for $M$. leprae was 9 to 10 times lower than the lowest value of the index that could be obtained with $M$. microti and $M$. avium, and 60 times lower than that for the closely related $M$. microti grown in host tissue (Table 4).

\section{Lack of direct uptake of purine nucleotides by M. leprae}

Apparent uptake of $\left[{ }^{14} \mathrm{C}\right] \mathrm{AMP}$ or $\left[{ }^{14} \mathrm{C}\right] \mathrm{GMP}$, and incorporation of the label into material, probably nucleic acids, insoluble in ICTCA only occurred with $M$. leprae when acid phosphatase 
Table 6. Incubation of $M$. leprae organisms with purine nucleotides

$M$. leprae organisms $\left(3 \times 10^{9}\right.$ to $\left.10^{10}\right)$ were incubated in incubation mixture (see Methods) with additions as indicated. Nucleotides present were either $\left[2-{ }^{3} \mathrm{H}\right] \mathrm{AMP}(17 \mu \mathrm{M} ; 1 \mu \mathrm{Ci})$ or $\left[\mathrm{U}-{ }^{14} \mathrm{C}\right] \mathrm{GMP}$ $(17 \mu \mathrm{M} ; 1 \mu \mathrm{Ci})$. Incubations were done in triplicate with nucleosides and GMP. However, five incubations were done using two isolates of $M$. leprae with AMP. In this Table, incorporation refers to radioactivity in acid soluble material; no further fractionation was done.

\begin{tabular}{|c|c|c|c|c|}
\hline \multirow[b]{2}{*}{ Incubation system } & \multicolumn{2}{|c|}{ AMP } & \multicolumn{2}{|c|}{ GMP } \\
\hline & $\begin{array}{l}\text { Incorporation } \\
\text { (d.p.m. per } \\
10^{10} \text { organisms } \\
\text { in } 24 \mathrm{~h} \text { ) }\end{array}$ & $\begin{array}{c}\text { Percentage } \\
\text { hydrolysed by } \\
10^{10} \text { organisms } \\
\text { in } 24 \mathrm{~h}\end{array}$ & $\begin{array}{l}\text { Incorporation } \\
\text { (d.p.m. per } \\
10^{10} \text { organisms } \\
\text { in } 24 \mathrm{~h} \text { ) }\end{array}$ & $\begin{array}{c}\text { Percentage } \\
\text { hydrolysed by } \\
10^{10} \text { organisms } \\
\text { in } 24 \mathrm{~h}\end{array}$ \\
\hline M. leprae & $20200 \pm 1890$ & 70 & $5350 \pm 50$ & 92 \\
\hline M. leprae $+10 \mathrm{~mm}-\mathrm{NaF}$ & $17200 \pm 3080$ & 50 & $2160 \pm 98$ & 66 \\
\hline $\begin{array}{l}\text { M. leprae }+10 \mathrm{~mm}-4 \text {-methylumbelliferyl } \\
\text { phosphate* }\end{array}$ & $10700 \pm 1590$ & 47 & $2100=0$ & ND \\
\hline $\mathrm{NaOH}$-treated $M$. leprae & $-\bar{\dagger}$ & - & $-\dagger$ & - \\
\hline $\begin{array}{l}\text { ND, Not done. } \\
- \text {, Not detectable }(<100 \text { d.p.m. per } 10 \\
\text { * Untreated } M \text {. leprae hydrolysed } 4 \text {-metl } \\
\text { while hydrolysis could not be detected } \mathrm{w} \\
\dagger \text { When supplied at } 17 \mu \mathrm{M} \text { and } 1 \mu \mathrm{Ci} \text { f } \\
\text { following rates: adenosine, } 29800 \pm 663 \\
10^{10} \text { organisms in } 24 \mathrm{~h}\end{array}$ & $\begin{array}{l}\text { organisms in } \\
\text { lumbelliferyl } \mathrm{p} \\
\mathrm{NaOH} \text {-treate } \\
\text { nucleosides }\end{array}$ & $\begin{array}{l}\text { h). } \\
\text { sphate at the rat } \\
M \text {. leprae. } \\
\text { e incorporated }\end{array}$ & $\begin{array}{l}30 \% \text { per } 10^{10} \\
\mathrm{NaOH}-\text { treated }\end{array}$ & Thisms in $24 \mathrm{~h}$, leprae at the \\
\hline
\end{tabular}

activity adsorbed from the host was present. The activity of this adsorbed phosphatase activity could be partially inhibited by $10 \mathrm{~mm}-\mathrm{NaF}$ and completely abolished by $\mathrm{NaOH}$ treatment of $M$. leprae (Wheeler et al., 1982), and in this work similar effects were observed on both incorporation of ${ }^{14} \mathrm{C}$ from $\left[{ }^{14} \mathrm{C}\right] \mathrm{AMP}$ or $\left[{ }^{14} \mathrm{C}\right] \mathrm{GMP}$ and the rates of hydrolysis of the nucleotides (Table 6). Furthermore, addition of 4-methylumbelliferyl phosphate to compete with nucleotides for the phosphatase also inhibited incorporation of label and hydrolysis of nucleotides.

In a previous study, $M$. leprae failed to take up ATP (Lee \& Colston, 1985). There was no evidence of hydrolysis of ATP followed by uptake of adenosine but relatively low numbers of bacteria were used and phosphatase activity would have been very low. Thus, $M$. leprae organisms do not take up purine nucleotides directly and if nucleotides are to be used as a source of the purine ring, the phosphate group(s) must be removed first by hydrolysis.

\section{Is the acquisition of purines a necessity for growth of $M$. leprae?}

The results presented above, although obtained with non-dividing organisms, suggest that $M$. leprae is not capable of synthesizing the purine ring de novo and thus requires the supply of a source of the purine ring in order to grow. However, the possibility that there may be unusually strong repression of purine biosynthesis in $M$. leprae in vivo compared with the other mycobacteria studied cannot be entirely ruled out. Further efforts to demonstrate purine biosynthesis in $M$. leprae, and to elucidate the regulation of purine metabolism in mycobacteria grown in vivo, by studying individual enzymes, are described in the following paper (Wheeler, 1987).

Whatever the explanation for the failure of $M$. leprae organisms harvested from armadillo tissue to synthesize the purine ring, it would be prudent to include purine(s) in any new attempts to grow $M$. leprae in axenic culture. The 'order of preference' for purines, judged by incorporation into nucleic acids (Khanolkar \& Wheeler, 1983) is adenosine $>$ hypoxanthine $>$ guanine $>$ adenine. As in $M$. avium and $M$. microti, both adenine and guanine nucleotides could be synthesized from any one of these substrates, as judged by the appearance of ${ }^{14} \mathrm{C}$ in both adenine and guanine of hydrolysed nucleic acids after incubation with any of the above ${ }^{14} \mathrm{C}$ labelled purines. 


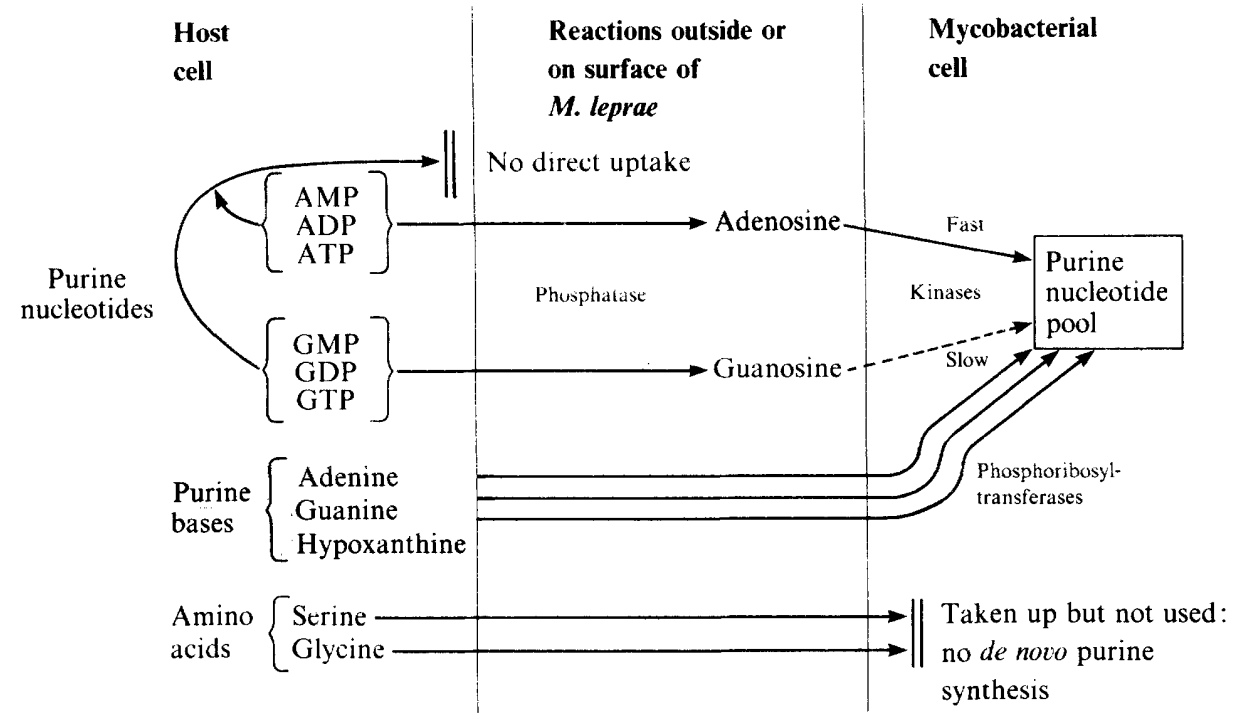

Fig. 3. Sources of the purine ring for nucleotides in intracellular $M$. leprae. Reactions indicated as occurring outside or on the surface of $M$. leprae are essentially speculative: the location of the enzymes of $M$. leprae and details of transport mechanisms for most substrates are not known. However, the reactions themselves shown as present or absent, and the metabolic fate of the sources of the purine ring shown when supplied extracellularly to $M$. leprae, are known.

In contrast with $M$. leprae, both $M$. avium and $M$. microti incorporated adenosine more slowly than either adenine or hypoxanthine. The rapid incorporation of adenosine by $M$. leprae together with the high specific activity of adenosine kinase in extracts (K hanolkar \& Wheeler, 1983) may reflect a greater commitment to an intracellular existence of $M$. leprae than of other pathogenic mycobacteria. Although free adenosine is at a very low concentration in animal tissues and is thus almost unavailable to a pathogen (Hartwick et al., 1979), adenine nucleotides are the most plentiful source of the purine ring in mammalian cells (Hunting et al., 1981; Lesse et $a l ., 1984$ ) and the ability of $M$. leprae to hydrolyse them to adenosine and rapidly incorporate the adenosine into purine nucleotides may be important (Fig. 3) for growth inside host cells. A further, intriguing possibility is that the relatively low $\mathrm{G}+\mathrm{C}$ content of $M$. leprae DNA in comparison with the high $\mathrm{G}+\mathrm{C}$ content in other mycobacteria - and thus the high $\mathrm{A}+\mathrm{T}$ content (Imaeda et al., 1982; Clark-Curtiss et al., 1985) - may reflect a crucial importance of adenine nucleotides in the nutrition of $M$. leprae.

I thank C. Ratledge for encouragement and helpful advice, and Kathleen Bulmer for excellent technical assistance. Armadillos were maintained using funds from LEPRA (British Leprosy Relief Association) or obtained from the WHO (IMMLEP) armadillo bank. This work was supported by MRC grant 983 22/33/T.

Chadwick, M. V. (1982). Mycobacteria. Institute of Medical Laboratory Sciences Monographs. Bristol: P. S. G. Wright.

Clark-Curtiss, J. E., JaCoks, W. R., Docherty, M. A., RITChIE, L. R \& CURTISS, R., III (1985). Molecular analysis of DNA and construction of genomic libraries of Mycobacterium leprae. Journal of Bacteriology 161, 1093-1102.

Evans, M. J., Newton, H. E. \& Levy, L. (1973). Early response of mouse footpads to Mycobacterium leprae. Infection and Immunity 7, 76-85.

Hartwick, R. A., Kistulovic, A. M. \& Brown, P. R. (1979). Identification and quantification of nucleosides, bases and other UV-absorbing compounds in serum, using reversed phase, high performance liquid chromatography. Journal of Chromatography 186, 659-676.

Heyworth, P. G., GutTeridge, W. E. \& Ginger, C. D. (1982). Purine metabolism in Trichomonas vaginalis. FEBS Letters 141, 106-110.

HoulberG, U. \& Jensen, K. F. (1983). Role of hypoxanthine and guanine in regulation of Salmonella typhimurium pur gene expression. Journal of Bacteriology 153, 837-845.

Hunting, D., Hardern, J. \& Henderson, J. F. (1981). Quantitative analysis of purine and pyrimidine metabolism in Chinese hamster ovary cells. Canadian Journal of Biochemistry 59, 838-847. 
IMAEDA, T., KIRChHEIMER, W. F. \& BaRKSDALE, L. (1982). DNA isolated from Mycobacterium leprae: genome size, base ratio, and homology with other related bacteria as determined by optical DNA-. DNA reassociation. Journal of Bacteriology 150, 414 . 417.

Khanolkar, S. R. \& Wheeler, P. R. (1983). Purine metabolism in Mycobacterium leprae grown in armadillo liver. FEMS Microbiology Letters 20. 273278.

LEE, Y. N. \& Colston, M. J. (1985). Measurement of ATP generation and decay in Mycobacterium leprae in vitro. Journal of General Microbiology 131, 3331 3337.

Lesse, H. J., Biggers, J. D., Mioz, E. A. \& Lechene, C. (1984). Nucleotides in a single mammalian ovum or preimplantation embryo. Analytical Biochemistry 140, 443-448.

Malathi, V. G. \& Ramakrishnan, T. (1966). Biosynthesis of nucleic acid purines in Mycobacterium tuberculosis $\mathrm{H}_{37} \mathbf{R}_{\mathrm{v}}$. Biochemical Journal 98, 594597.

Marz, R., Wohlhenter, R. M. \& Plagemann, G. W. (1979). Purine and pyrimidine transport and phosphorylation and the interaction in overall uptake by cultured mammalian cells. Journal of Biological Chemistry 254, 2329-2338.

MOR, N. (1983). Intracellular location of Mycobacterium leprae in macrophages of normal and immunodeficient mice and effect of rifampicin. Infection and Immunity 42, 802-811.

Moulder, J. W. (1985). Comparative biology of intracellular parasitism. Microbiological Reviews 49, 298-337.

Nierlich, D. P. \& Magasanik, B. (1965). Regulation of purine ribonucleotide synthesis by end product inhibition. Journal of Biological Chemistry 240, 358 365 .
Nierlich, D. P. \& Magasanik, B. (1971). Control by feedback repression of the enzymes of purine biosynthesis in Aerobacter aerogenes. Biochimica et biophysica acta 230, 349-361.

Ramakrishnan, T., Murthy, P. S. \& Gopinathan, K. P. (1972). Intermediary metabolism of mycobacteria. Bacteriological Reviews 36, 65-108.

Sherman, I. W. (1979). Biochemistry of Plasmodium (malarial parasites). Microbiological Reviews 43, 453495.

Turnbough, C. L., JR \& Switzer, R. L. (1975). Oxygen-dependent inactivation of glutamine phosphoribosylpyrophosphate amidotransferase in vitro: model for in vivo inactivation. Journal of Bacteriology 121, 115-120.

WheEleR, P. R. (1984). Oxidation of carbon sources through the tricarboxylic acid cycle in Mycobacterium leprae grown in armadillo liver. Journal of General Microbiology 130, 381-389.

WheEler, P. R. (1987). Enzymes for purine synthesis and scavenging in pathogenic mycobacteria and their distribution in Mycobacterium leprae. Journal of General Microbiology 133, 3013-3018.

WHEELER, P. R. (1988). Measurement of hypoxanthine incorporation in purified suspensions of Mycohacterium leprae: a suitable method to screen for antileprosy agents in vitro. Journal of Medical Microbiology (in the Press).

WheEler, P. R., BharadwaJ, V. P. \& GREgory, D. (1982). $\quad N$-Acetyl- $\beta$-glucosaminidase, $\beta$-glucuronidase and acid phosphatase in Mycobacterium leprae. Journal of General Microbiology 128, 1063-1071.

WORLd HEalth ORGanization (1980). UNDP/World Bank/WHO Special Programme for Research and Training in Tropical Diseases. Report of the Fifth Meeting on the Immunology of Leprosy (IMMLEP). TDR/IMMLEP-SWG (5)/80.3, Annex 4, p. 23. Geneva: World Health Organization. 